\title{
Synthesis and Ultraviolet Visible Spectroscopy Studies of Chitosan Capped Gold Nanoparticles and Their Reactions with Analytes
}

\author{
Norfazila Mohd Sultan and Mohd Rafie Johan \\ Nanomaterials Engineering Research Group, Advanced Materials Research Laboratory, Department of Mechanical Engineering, \\ University of Malaya, 50603 Lembah Pantai, Kuala Lumpur, Malaysia
}

Correspondence should be addressed to Mohd Rafie Johan; mrafiej@um.edu.my

Received 29 April 2014; Revised 10 July 2014; Accepted 16 July 2014; Published 19 August 2014

Academic Editor: Degang Fu

Copyright (C) 2014 N. Mohd Sultan and M. R. Johan. This is an open access article distributed under the Creative Commons Attribution License, which permits unrestricted use, distribution, and reproduction in any medium, provided the original work is properly cited.

Gold nanoparticles (AuNPs) had been synthesized with various molarities and weights of reducing agent, monosodium glutamate (MSG), and stabilizer chitosan, respectively. The significance of chitosan as stabilizer was distinguished through transmission electron microscopy (TEM) images and UV-Vis absorption spectra in which the interparticles distance increases whilst retaining the surface plasmon resonance (SPR) characteristics peak. The most stable AuNPs occurred for composition with the lowest (1 g) weight of chitosan. AuNPs capped with chitosan size stayed small after 1 month aging compared to bare AuNPs. The ability of chitosan capped AuNPs to uptake analyte was studied by employing amorphous carbon nanotubes $(\alpha-\mathrm{CNT})$, copper oxide $\left(\mathrm{Cu}_{2} \mathrm{O}\right)$, and zinc sulphate $\left(\mathrm{ZnSO}_{4}\right)$ as the target material. The absorption spectra showed dramatic intensity increased and red shifted once the analyte was added to the chitosan capped AuNPs.

\section{Introduction}

Gold nanoparticles (AuNPs) have glowing prospects in many applications due to their distinctive optical, electronic, and electrical properties [1]. AuNPs display intense colours when induced by incident light field. These were contributed by collective electron oscillation that gives intensification to the surface plasmon resonance (SPR) absorption.

There are various techniques to produce AuNPs such as microemulsion, reversed micelles, seeding growth, sonochemistry, photochemistry, radiolysis, and direct chemical reduction [2-4]. The most simple, economical, and powerful synthesis is the direct chemical reduction method. In the case of AuNPs, chemical reduction routes generate zerovalent gold colloids from gold precursors [5].

The invention of zerovalent gold colloids was pioneered by Turkevich et al. [6] and later refined by Frens [7] in which the ratio of gold precursors to citrate was varied. BrustSchiffin [8] commenced the synthesis of AuNPs in organic solvents which involves a phase transfer agent such as toluene.
The above conventional methods had many shortcomings which contributed to explorations of other reducing agents and alternative routes. The synthesis of AuNPs through Turkevich et al. approaches takes a longer time $(1 \mathrm{hr})$ for gold salt reduction. While the use of organic solvents in BrustSchiffin method leaves them inapt for detecting biomolecules and biological surfaces like proteins and saccharides [9], various chemicals had been exploited as reducing agent to produce zerovalent gold colloids such as amino acid derivatives like lysine and valine but without success. However, other acidic amino acid derivatives such as aspartic acid [10] and monosodium glutamate (MSG) [11] are competent in reducing gold salt (Figure 1). Sugunan and Dutta [11] produced AuNPs by emphasizing on lower molar ratio of MSG.

AuNPs have compelling tendency to flocculate due to their van der walls forces. However, the agglomeration can be hindered by introducing a repulsive force between the particles. In this light, the use of stabilizer as a repulsive force came into the picture. The use of chitosan as a stabilizer 


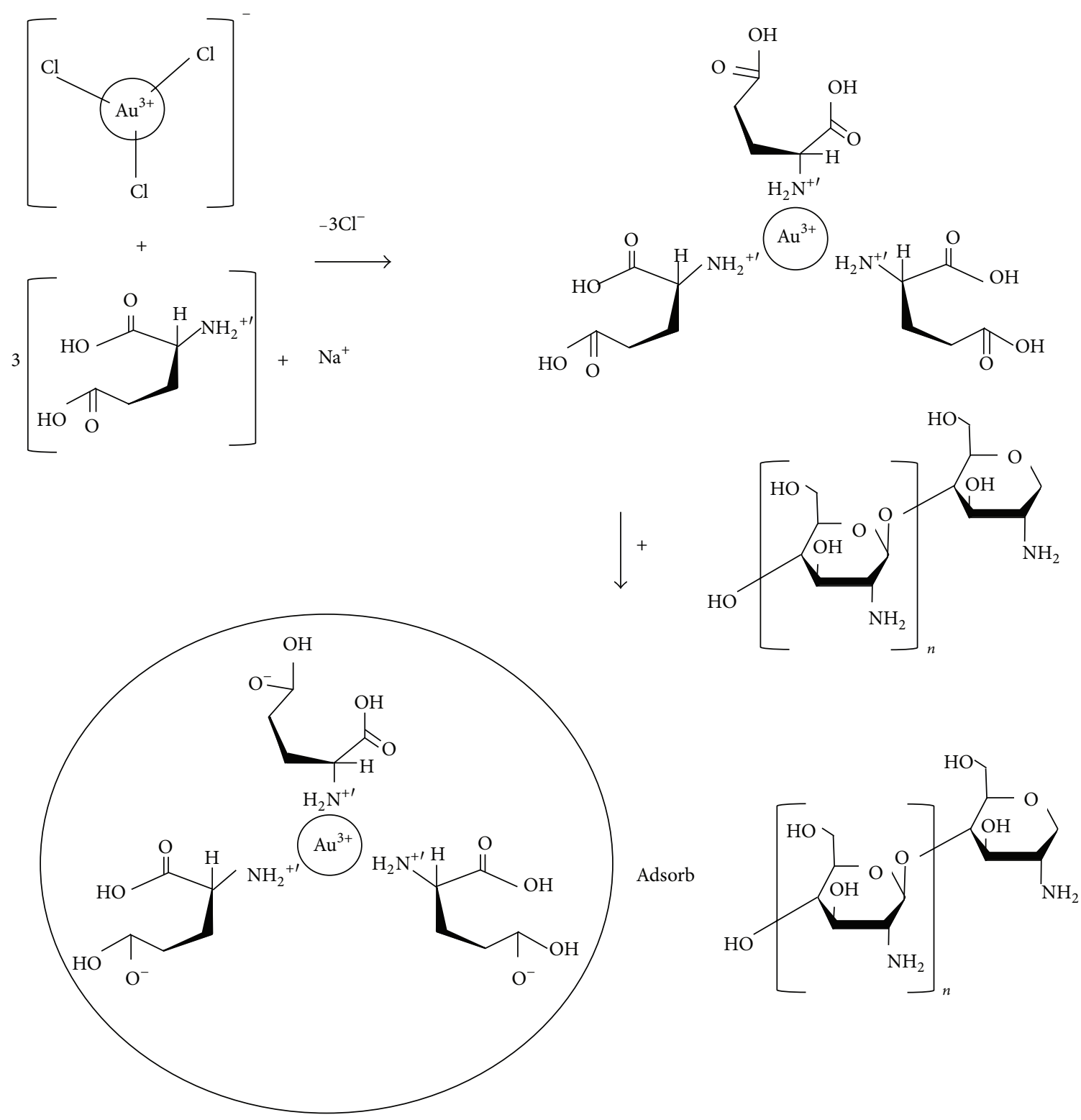

FIGURE 1: Schematic diagram of gold precursor reduction by MSG and capping the gold particle surfaces with chitosan.

was reported elsewhere [12]. Chitosan contributed the steric hindrance to stabilize the nanoparticles as shown in Figure 1. The amino group presence in its polycationic structure activates steric hindrance, thus ensuring strong stability over long durations [12]. For most biological applications, chitosan possesses many attractive functional groups such as biotin [13], aptamers [14,15], concanavalin (con-A) [16], and bovine serum albumin $[17,18]$. However, proteins have a downside as they are expensive although they were widely exploited and offer excellent characteristics. Remarkably, chitosan possesses similar ability as proteins and manipulations of its properties have not been fully extended for numerous applications. Chitosan is accessible for cross-linking through its boundless amino group and its cationic features allowing the ionic crosslinking to take place with multivalent elements. The most promising features of chitosan are its solubility in aqueous acidic solutions [19]. The description of chitosan agrees with the aims of the research to manufacture a readily biocompatible and nontoxic chitosan capped gold nanoparticles.

Sugunan et al. [9] had employed chitosan as stabilizer for silver nanoparticles for heavy metal ion sensor, yet the thermodynamically proficiency of chitosan had not been investigated. Moreover, the performance of chitosan adsorption on the surface of AuNPs has not been studied. In this paper, we report the synthesis of AuNPs and its stabilization mechanism using chitosan. By exploiting the chemistry of amine and chitosan, we have shown that the AuNPs can be prepared in water by complexation of high molar ratio glutamic acid molecules with gold precursors stabilized by the adsorption of chitosan on the surface of AuNPs. Preparation of AuNPs capped with chitosan was carried out in a single-pot process and the resulting particles 
were thoroughly characterized. The stability of chitosan was furthered studied and discussed.

\section{Experimental Section}

2.1. Materials. Gold (III) chloride $\left(\mathrm{AuCl}_{3}\right)$, acetic acid, and monosodium glutamate (MSG) $(99 \% \mathrm{Na}$ salt of L-glutamic acid) were purchased from Acros Organics. Meanwhile, chitosan (industrial grade) was purchased from Easter Holding Co. Ltd. with deacetylation degree of $80 \%$. All chemicals were used without further purifications and all the solutions were prepared with distilled water.

2.2. Preparation of AuNPs. $2 \mathrm{~mL}$ of $5 \mathrm{mM} \mathrm{AuCl}_{3}$ solution $\left(0.1517 \mathrm{~g}\right.$ in $100 \mathrm{~mL}$ water) was stirred and heated to $100^{\circ} \mathrm{C}$. Then, $3 \mathrm{~mL}$ of $50 \mathrm{mM}$ Na salt of L-glutamic acid solution (MSG) $(0.9357 \mathrm{~g}$ in $100 \mathrm{~mL}$ water) is quickly poured into the gold solution. The solution was stirred continuously until the colour changed from pale red to intense red. The steps were repeated with 100, 150, 200, 250, and $300 \mathrm{mM}$ of MSG. Another set of samples was prepared for observing the aging behaviour of the AuNPs. The samples were left in ambience temperature for a month.

2.3. Preparation of Chitosan Capped AuNPs. The chitosan solution was prepared by mixing the said amount of blended chitosan powder as purchased with distilled water and adequate amount of acetic acid. The solution was stirred at room temperature until the chitosan powder had completely dissolved in the water. $990 \mu \mathrm{L}$ of chitosan solution (1g of chitosan in mixture of $100 \mathrm{~mL}$ water and $150 \mu \mathrm{L}$ acetic acid) was then added to the as-synthesized $50 \mathrm{mM}$ of MSG reduced AuNPs. A visible change of colour occurred immediately. The heating was discontinued to allow the solution to reach the ambient temperature. The steps were repeated with different concentrations of MSG $(100,150,200,250$, and $300 \mathrm{mM})$. Another set of samples was prepared for observing the aging behaviour of the chitosan capped AuNPs. The samples were left in ambience temperature for a month.

\subsection{Preparation of Amorphous Carbon Nanotubes ( $\alpha$-CNTs)} Chitosan Capped AuNPs. The synthesis procedure of $\alpha$-CNTs is followed by Tan et al. [20]. The procedure was instigated with mixture of $8 \mathrm{~mL}$ of ethyl alcohol (90\%), $4.2 \mathrm{~g}$ of $\mathrm{NaBH}_{4}$ (99.99\%), and $15 \mathrm{~mL}$ of $1 \mathrm{M} \mathrm{NaOH}$ in a $25 \mathrm{~mL}$ flask. The solution was further stirred for the next 45 minutes before being transferred to a Parr reactor with capacity of $200 \mathrm{~mL}$. The reactor was heated inside a furnace up to $200^{\circ} \mathrm{C}$ and held for 2 hours under scaled condition. The Parr reactor was allowed to cool to ambient temperature and the precipitate was washed thoroughly with alcohol and deionised water. The precipitate was then dried in the vacuum oven. $\alpha$-CNTs were added to the optimum condition of chitosan capped AuNPs solution ( $1 \mathrm{~g}$ of chitosan powder and $100 \mathrm{mM}$ of MSG).

2.5. Preparation of Copper Oxide-Chitosan Capped AuNPs. $0.005,0.01,0.05,0.1$, and $0.5 \mathrm{~g}$ of purchased copper oxide powder were added to optimum condition of chitosan capped

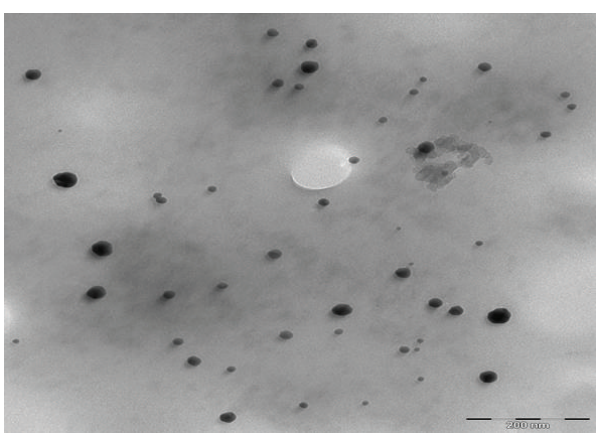

Figure 2: TEM image of AuNPs reduced with 100 mM of MSG.

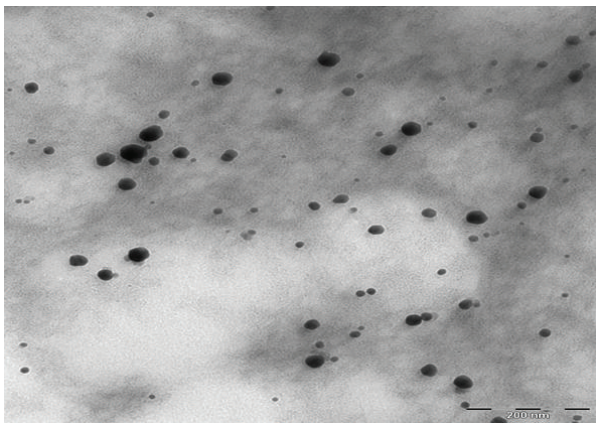

FIGURE 3: TEM image of AuNPs reduced with $200 \mathrm{mM}$ of MSG.

AuNPs solution (1 $\mathrm{g}$ of chitosan powder and $100 \mathrm{mM}$ of MSG).

2.6. Preparation of Zinc Sulphate-Chitosan Capped AuNPs. $0.005,0.01,0.05,0.1$, and $0.5 \mathrm{~g}$ of purchased zinc sulphate powder were added to optimum condition of chitosan capped AuNPs solution ( $\mathrm{g}$ of chitosan powder and $100 \mathrm{mM}$ of MSG).

2.7. Characterizations of AuNPs. Transmission electron microscope (Libra 120 TEM using accelerating voltage of $400 \mathrm{kV}$ ) was employed to assess the particles size and distribution of the particles. The optical properties of gold dispersions were investigated by UV-Vis spectrophotometer using UVIKON 923 UV-Vis spectrophotometer.

\section{Results and Discussion}

3.1. TEM Analysis. Figures 2, 3, and 4 show the TEM images for AuNPs prepared at different concentrations of MSG. The particles are nearly spherical with high dispersibility. The average size of particles for 100, 200, and $300 \mathrm{mM} \mathrm{MSG}$ is 18, 15 , and $9 \mathrm{~nm}$, respectively. It is clearly shown that high molar of MSG produces smaller particle size.

The role of chitosan in steric mechanism has been verified by the TEM image shown in Figure 5 . The chitosan which resembles a spider web infused a repelling force between the AuNPs separating them apart unlike the bare AuNPs (Figures 2-4). The average interparticles distance increases to $96 \mathrm{~nm}$ due to wrapping of chitosan around the AuNPs. 


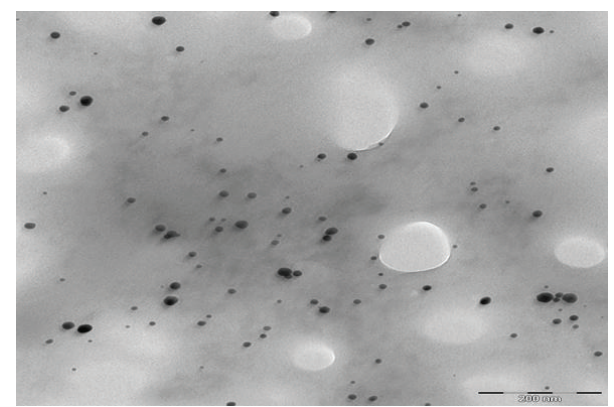

FIGURE 4: TEM image of AuNPs reduced with $300 \mathrm{mM}$ of MSG.

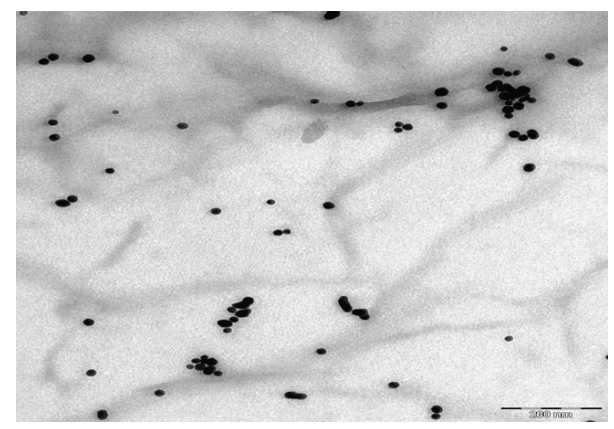

FIGURE 5: TEM image of chitosan capped AuNPs.

\subsection{UV-Vis Spectroscopy Analysis}

3.2.1. Effect of Concentration of Reducing Agent MSG. Figure 6 shows the absorption spectra of AuNPs at various concentrations of MSG. The surface plasmon resonance (SPR) peaks are shifted to the smaller wavelengths indicating the reduction in particle sizes. This result is in good agreement with the TEM images in Figures 2-4. The symmetrical shape of the absorp-tion spectra indicates that sample has a narrow particle size distribution.

3.2.2. Effect of Chitosan as Stabilizer. Figure 7 shows the absorption spectra of bare and increased weight of chitosan capped AuNPs at the optimum concentration of reducing agent MSG (100 mM). The absorbance of chitosan capped AuNPs is higher than bare AuNPs. The SPR peak is shifted to the longer wavelength for chitosan capped AuNPs. This red shifted trend is continued for samples with increasing weight of chitosan. The absorbance for chitosan capped AuNPs is slightly increased with the increase of chitosan weight. The attachment of chitosan on the surface of AuNPs affected their optical properties.

3.2.3. Effect of Aging. Figure 8 shows the absorption spectra of AuNPs with various concentrations of MSG after 1 month aging time. The SPR peaks are shifted to longer wavelength compared to their counterparts in Figure 6. The same goes for their FWHM values which show more broadened peak after 1 month ageing time. This indicates that the AuNPs size and their particle size distribution are increased after aging.

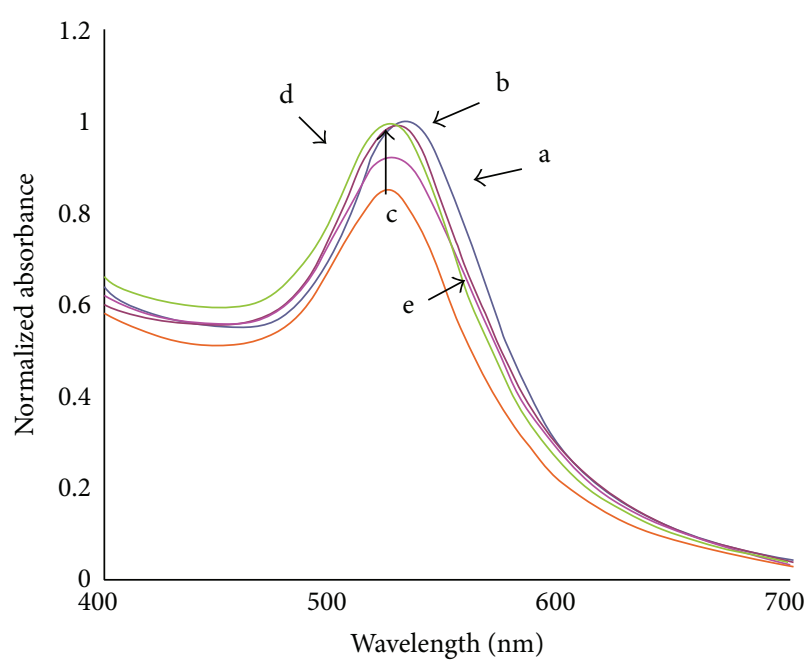

FIGURE 6: Absorption spectra of AuNPs with various concentrations of reducing agent MSG: (a) $100 \mathrm{mM}$; (b) $150 \mathrm{mM}$; (c) $200 \mathrm{mM}$; (d) $250 \mathrm{mM}$; (e) $300 \mathrm{mM}$.

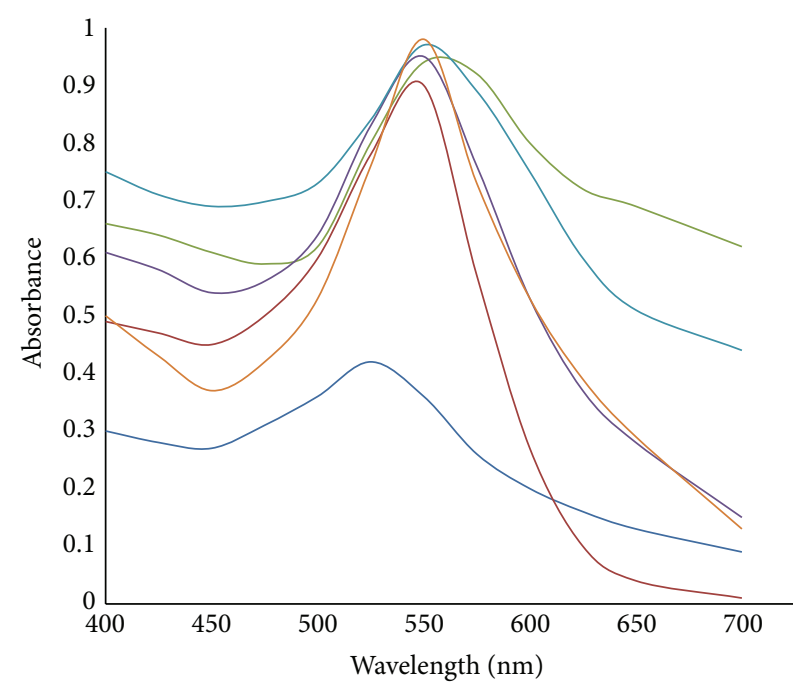
- (a) Without chitosan
(d) $3 \mathrm{~g}$ chitosan
(b) $1 \mathrm{~g}$ chitosan
(e) $4 \mathrm{~g}$ chitosan
- (c) $2 \mathrm{~g}$ chitosan
- (f) $5 \mathrm{~g}$ chitosan

FIGURE 7: Absorption spectra of bare and increased weight of chitosan capped AuNPs at the optimum concentration of reducing agent MSG: (a) $0 \mathrm{~g}$ chitosan; (b) $1 \mathrm{~g}$ chitosan; (c) $2 \mathrm{~g}$ chitosan; (d) $3 \mathrm{~g}$ chitosan; (e) $4 \mathrm{~g}$ chitosan; (f) $5 \mathrm{~g}$ chitosan.

Figure 9 shows the absorption spectra of bare and chitosan capped AuNPs for various concentrations of MSG after 1 month ageing time. The SPR peaks are shifted to the smaller wavelength compared to the bare AuNPs (Figure 8). The same goes for their FWHM values which are smaller than the FWHM values of the bare AuNPs. These absorption spectra have highlighted the role of chitosan adsorption on the AuNPs surfaces, in which their particle size stays small even after 1 month aging time. Chitosan preserves stability 
TABLE 1: Experimental values of SPR peaks for bare and chitosan capped AuNPs with full width half maximum (FWHM) after 1 month ageing time.

\begin{tabular}{lcccc}
\hline $\begin{array}{l}\text { Sample } \\
\text { Concentration of MSG }(\mathrm{mM})\end{array}$ & SPR $\lambda_{\max }(\mathrm{nm})$ & \multicolumn{2}{c}{ FHWM (nm) } \\
Chitosan capped AuNPs & AuNPs & 51 & 60 \\
\hline 100 & 532 & 531 & 72 & 52 \\
150 & 544 & 537 & 52 & 51 \\
200 & 554 & 539 & 96 & 46 \\
250 & 544 & 527 & 70 & 57 \\
300 & 534 & 526 & & \\
\hline
\end{tabular}

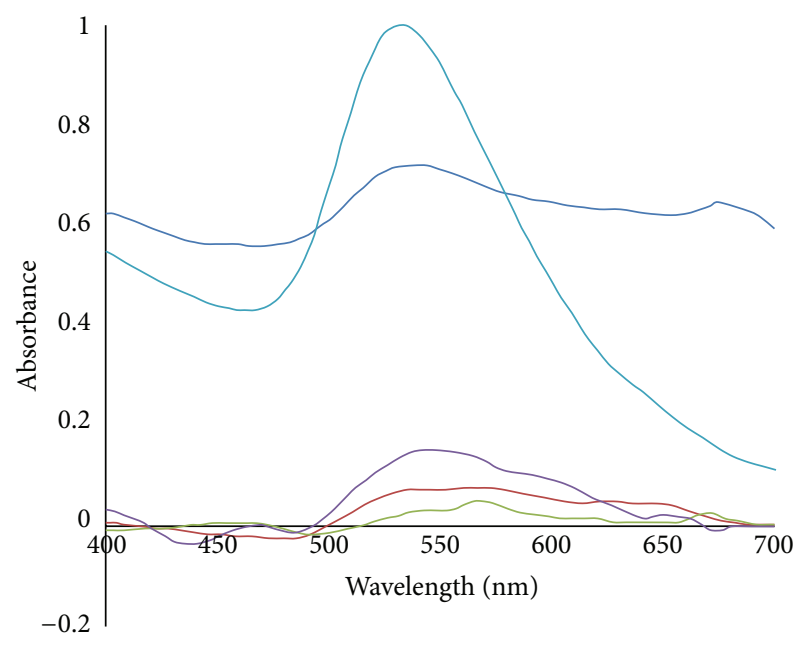

$\begin{array}{ll}\text { (a) } 100 \mathrm{mM} & \text { (d) } 250 \mathrm{mM} \\ \text { (b) } 150 \mathrm{mM} & \text { (e) } 300 \mathrm{mM} \\ \text { (c) } 200 \mathrm{mM} & \end{array}$

FIGURE 8: Absorption spectra of AuNPs with various concentrations of reducing agent MSG after 1 month aging time: (a) $100 \mathrm{mM}$; (b) $150 \mathrm{mM}$; (c) $200 \mathrm{mM}$; (d) $250 \mathrm{mM}$; (e) $300 \mathrm{mM}$.

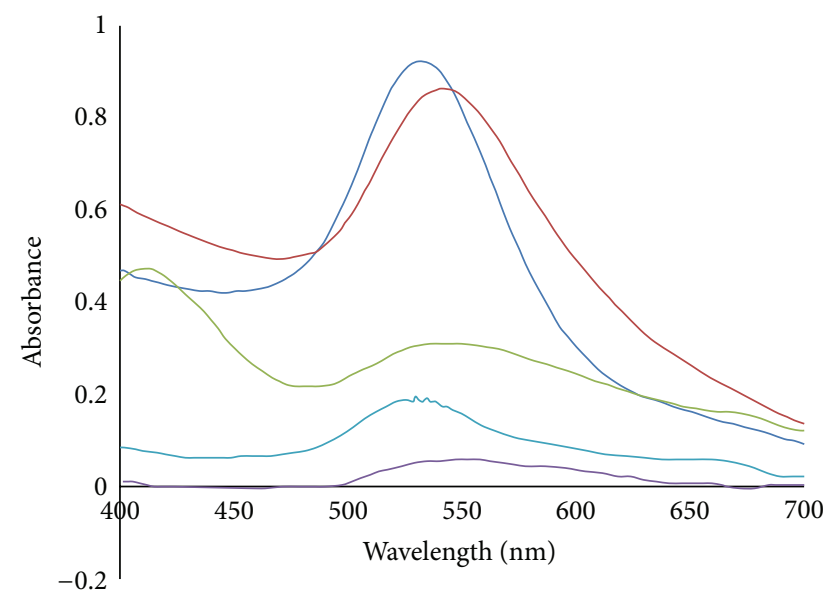
(a) $100 \mathrm{mM}$
- (d) $250 \mathrm{mM}$
(b) $150 \mathrm{mM}$
(e) $300 \mathrm{mM}$
(c) $200 \mathrm{mM}$

FIgURE 9: Absorption spectra of chitosan capped AuNPs with various concentrations of reducing agent MSG after 1 month aging time: (a) $100 \mathrm{mM}$; (b) $150 \mathrm{mM}$; (c) $200 \mathrm{mM}$; (d) $250 \mathrm{mM}$; (e) $300 \mathrm{mM}$.

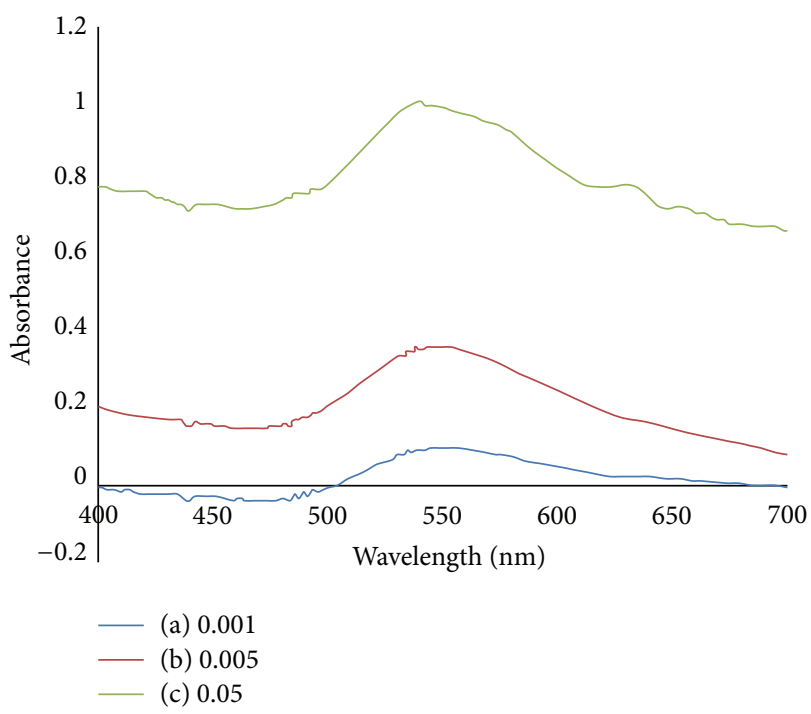

FIgURE 10: Absorption spectra of chitosan capped AuNPs mixed with different weights of $\alpha$-CNTs: (a) $0.001 \mathrm{~g}$; (b) $0.005 \mathrm{~g}$; (c) $0.05 \mathrm{~g}$.

and hinders agglomeration of AuNPs. The FWHM and other experimental results are listed in Table 1.

3.2.4. Effect of Amorphous Carbon Nanotube $(\alpha-C N T s)$ s, Oxides, and Sulphate to Chitosan Capped AuNPs. Figure 10 shows the SPR peaks of chitosan capped AuNPs adjourned at $549 \mathrm{~nm}$ for three different weights of $\alpha$-CNTs. The SPR peak intensity rises as the weight of $\alpha$-CNTs increases. This phenomenon can be explained with regard to the fact that AuNPs are very sensitive in the weight change of $\alpha$-CNTs upon exposure. High surface ratios of AuNPs contribute to the sensitivities and make them more reactive and able to uptake the analyte.

Figure 11 shows the absorption spectra of chitosan capped AuNPs mixed with different weights of copper oxide. The SPR peaks are shifted from 521 to $577 \mathrm{~nm}$ as the weight of copper oxide increases. This clearly shows the complexation of chitosan capped AuNPs towards the addition of copper oxide. The enlargement of the particles uptake can be underlined as the peak intensity also shows dramatic increase as the weight of copper oxide increases.

Figure 12 shows the absorption spectra of chitosan capped AuNPs at different weights of zinc sulphate. The spectra also successfully show analyte particles entrapment by chitosan 


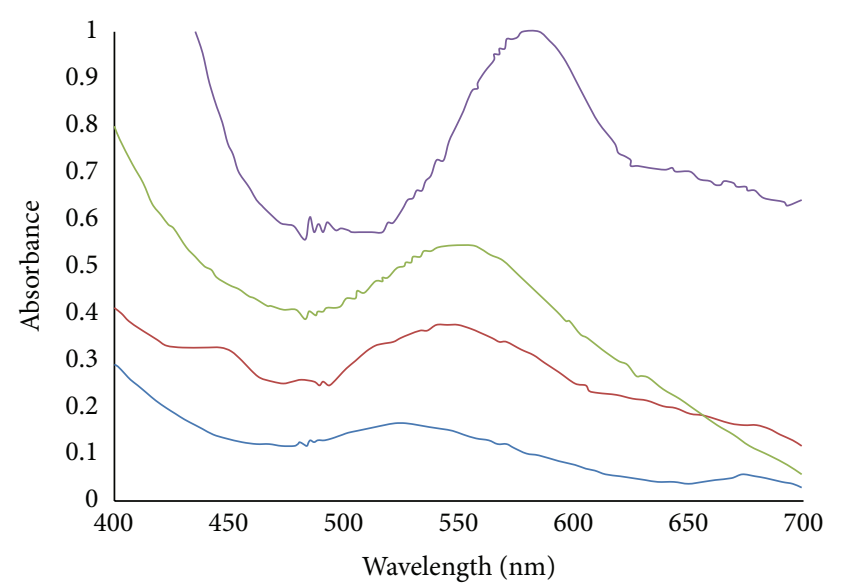
(a) 0.005
(c) 0.05

(b) 0.01

(d) 0.1

FIGURE 11: Absorption spectra of chitosan capped AuNPs mixed with different weights of copper oxide: (a) $0.005 \mathrm{~g}$; (b) $0.01 \mathrm{~g}$; (c) $0.05 \mathrm{~g}$; (d) $0.1 \mathrm{~g}$.

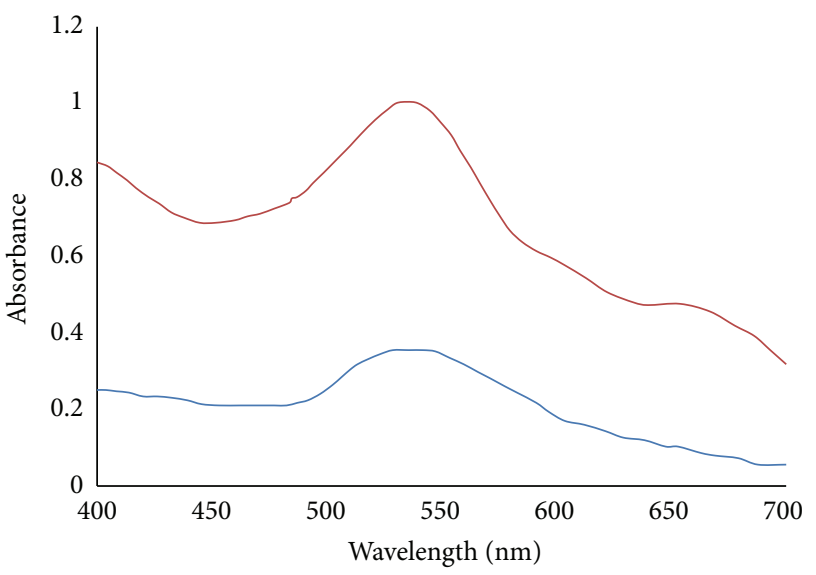

(a) 0.01

(b) 0.05

FIGURE 12: Absorption spectra of chitosan capped AuNPs mixed at different weights of zinc sulphate (a) $0.01 \mathrm{~g}$; (b) $0.05 \mathrm{~g}$.

capped AuNPs. The SPR peaks intensities are increased as the weight of zinc sulphate added to the chitosan capped AuNPs increases.

\section{Conclusion}

We have successfully synthesized chitosan capped AuNPs via chemical reduction technique. We have also revealed that AuNPs revolutionize their dimension and optical behaviour through variation of parameters such as concentration of reducing agent, weight of stabilizer, and aging time. Chitosan concentration plays an important role in imparting extra hindrance strength. The particles stability was contributed by chitosan even after 1 month of aging. The chitosan capped
AuNPs were able to uptake analyte such as $\alpha$-CNTs, copper oxide, and zinc sulphate.

\section{Conflict of Interests}

The authors declare that there is no conflict of interests regarding the publication of this paper.

\section{Acknowledgments}

The authors would like to express their greatest gratitude to the Ministry of Higher Education of Malaysia and University of Malaya for funding through UM/MOHE-HIR Research Grant (UM.C/HIR/MOHE/ENG/12). Special thanks are due to Mr. Low Chien Chong for providing the TEM images.

\section{References}

[1] D. A. Handley, Colloidal Gold: Principles, Methods, and Applications, Academic Press, New York, NY, USA, 1989, edited by M. A. Hayat.

[2] C. Roos, M. Schmidt, J. Ebenhoch, F. Baumann, B. Deubzer, and J. Weis, "Design and synthesis of molecular reactors for the preparation of topologically trapped gold clusters," Advanced Materials, vol. 11, no. 9, pp. 761-766, 1999.

[3] R. G. Freeman, M. B. Hommer, K. C. Grabar, M. A. Jackson, and M. J. Natan, "Ag-clad Au nanoparticles: novel aggregation, optical, and surface-enhanced Raman scattering properties," Journal of Physical Chemistry, vol. 100, no. 2, pp. 718-724, 1998.

[4] L. Cao, P. Diao, L. Tong, T. Zhu, and Z. Liu, "Surfaceenhanced Raman scattering of $\mathrm{p}$-aminothiophenol on a $\mathrm{Au}$ (core) $/ \mathrm{Cu}$ (shell) nanoparticle assembly," ChemPhysChem, vol. 6, no. 5, pp. 913-918, 2005.

[5] N. Toshima and T. Yonezawa, "Bimetallic nanoparticles: novel materials for chemical and physical applications," New Journal of Chemistry, vol. 22, no. 11, pp. 1179-1201, 1998.

[6] J. Turkevich, P. C. Stevenson, and J. Hillier, "A study of the nucleation and growth processes in the synthesis of colloidal gold," Discussions of the Faraday Society, vol. 11, pp. 55-75, 1951.

[7] J. Frens, "Controlled nucleation for the regulation of the particle size in monodisperse gold suspensions," Nature Physical Science, vol. 241, pp. 20-22, 1973.

[8] M.-C. Daniel and D. Astruc, "Gold nanoparticles: assembly, supramolecular chemistry, quantum-size-related properties, and applications toward biology, catalysis, and nanotechnology," Chemical Reviews, vol. 104, no. 1, pp. 293-346, 2004.

[9] A. Sugunan, C. Thanachayanont, J. Dutta, and J. G. Hilborn, "Heavy-metal ion sensors using chitosan-capped gold nanoparticles," Science and Technology of Advanced Materials, vol. 6, no. 3-4, pp. 335-340, 2005.

[10] S. Mandal, P. R. Selvakannan, S. Phadtare, R. Pasricha, and M. Sastry, "Synthesis of a stable gold hydrosol by the reduction of chloroaurate ions by the amino acid, aspartic acid," Journal of Chemical Sciences, vol. 114, no. 5, pp. 513-520, 2002.

[11] A. Sugunan and J. Dutta, "Novel synthesis of gold nanoparticles in aqueous media," in Proceedings of the Material Research Society Fall Conference, MRS, Boston, Mass, USA, 1999.

[12] H. C. Warad, S. C. Ghosh, C. Thanachayanont, and J. Dutta, "Highly luminescent manganese doped $\mathrm{ZnS}$ quantum dots for biological labeling," in Proceedings of International Conference 
on Smart Materials, Smart/Intelligent Materials and Nanotechnology (SmartMat '04), pp. 203-207, Chiang Mai, Thailand, 2004.

[13] N. Nath and A. Chilkoti, "Label-free biosensing by surface plasmon resonance of nanoparticles on glass: optimization of nanoparticle size," Analytical Chemistry, vol. 76, no. 18, pp. 5370-5378, 2004.

[14] V. Pavlov, Y. Xiao, B. Shlyahovsky, and I. Willner, "Aptamerfunctionalized Au nanoparticles for the amplified optical detection of thrombin," Journal of the American Chemical Society, vol. 126, no. 38, pp. 11768-11769, 2004.

[15] C. Huang, Y. Huang, Z. Cao, W. Tan, and H. Chang, "Aptamermodified gold nanoparticles for colorimetric determination of platelet-derived growth factors and their receptors," Analytical Chemistry, vol. 77, no. 17, pp. 5735-5741, 2005.

[16] D. C. Hone, A. H. Haines, and D. A. Russell, "Rapid, quantitative colorimetric detection of a lectin using mannose-stabilized gold nanoparticles," Langmuir, vol. 19, no. 17, pp. 7141-7144, 2003.

[17] K. Fujiwara, H. Watarai, H. Itoh, E. Nakahama, and N. Ogawa, "Measurement of antibody binding to protein immobilized on gold nanoparticles by localized surface plasmon spectroscopy," Analytical and Bioanalytical Chemistry, vol. 386, no. 3, pp. 639644, 2006.

[18] F. Frederix, J. Friedt, K. Choi et al., "Biosensing based on light absorption of nanoscaled gold and silver particles," Analytical Chemistry, vol. 75, no. 24, pp. 6894-6900, 2003.

[19] F. L. Mi, S. S. Shyu, C. Y. Kuan, S. T. Lee, K. T. Lu, and S. F. Ajng, "Chitosan-polyelectrolyte complexation for the preparation of gel beads and controlled release of anticancer drug. I. Effect of phosphorus polyelectrolyte complex and enzymatic hydrolysis of polymer," Journal of Applied Polymer Science, vol. 74, pp. 1868-1879, 1999.

[20] K. H. Tan, R. Ahmad, B. F. Leo, M. C. Yew, B. C. Ang, and M. R. Johan, "Physico-chemical studies of amorphous carbon nanotubes synthesized at low temperature," Materials Research Bulletin, vol. 47, no. 8, pp. 1849-1854, 2012. 

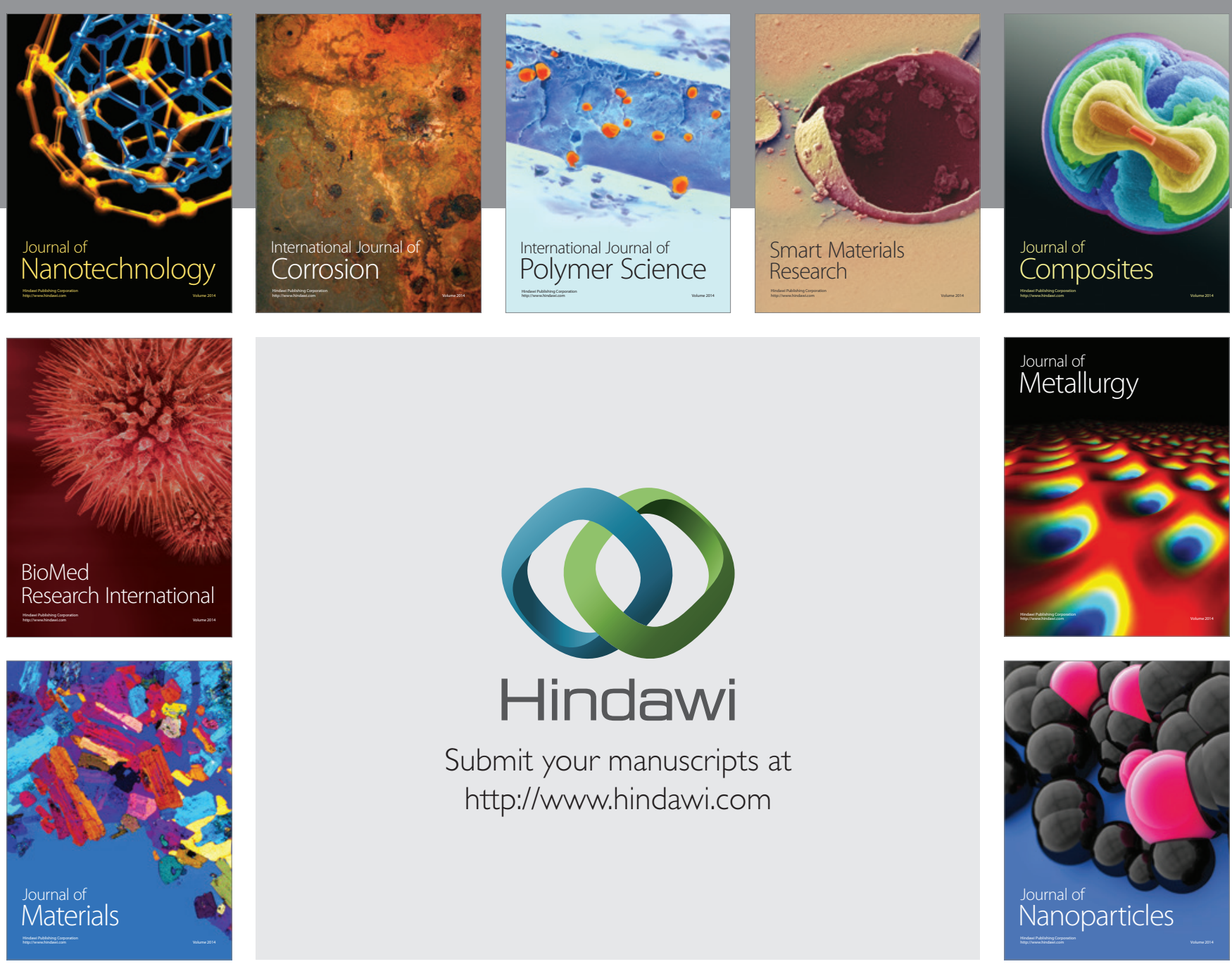

Submit your manuscripts at http://www.hindawi.com
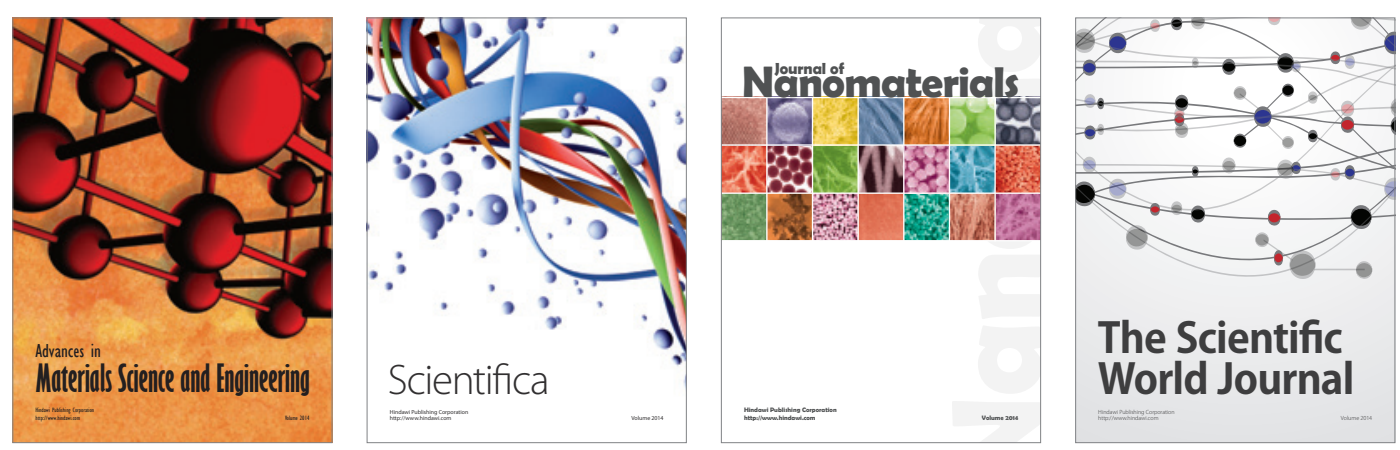

\section{The Scientific World Journal}
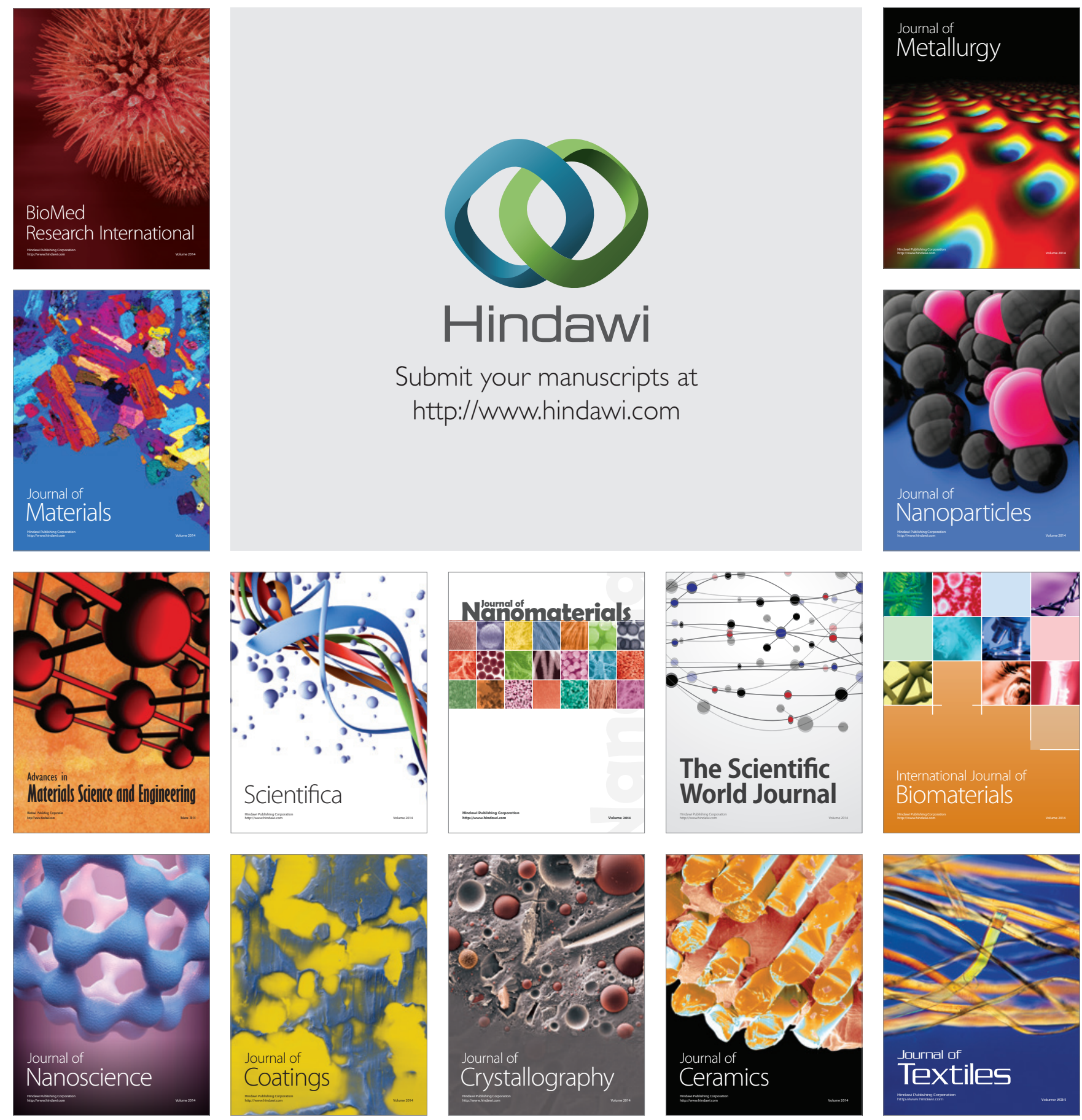